\title{
Fis-Mat Integrated Physics and Mathematics: A Proposal for a Curricular Sequence
}

\author{
Prof. Angeles Dominguez, Tecnologico de Monterrey (ITESM)
}

Angeles Dominguez is a Professor of the Department of Mathematics within the School of Engineering, a researcher at the School of Education, and the Chair of the Master of Education at the Tecnologico de Monterrey, Mexico. Also, she is currently collaborating with the School of Engineering at the University Andres Bello at Santiago, Chile. Angeles holds a bachelor degree in Physics Engineering from Tecnologico de Monterrey and a doctoral degree in Mathematics Education from Syracuse University, New York. Professor Dominguez is a member of the Researchers' National System in Mexico (SNI) and currently she is the President of Red de Investigación e Innovación en Educación del Noreste de México (REDIIEN). Angeles has been a visiting researcher at Syracuse University, at the University of Texas at Austin. She teaches undergraduate courses in Mathematics and graduate courses in Education. Professor Dominguez is a thesis advisor on the master and doctoral programs on education at the Tecnologico de Monterrey. Her main research areas are: a) models and modeling, b) use of technology to improve learning and c) evaluation. In addition, Professor Dominguez is the coordinator of the conTIgo T3 Latin America group that focuses on an effective and efficient use of the Texas Instrument technology in the mathematics and science classroom, and is member of the Executive Committee of international association (ASEE-EPPD and ICTMA).

\section{Dr. Jorge Eugenio de la Garza Becerra, Tecnologico de Monterrey (ITESM)}

Jorge de la Garza is a Lecturer of the Physics Department within the School of Engineering at the Tecnologico de Monterrey, Monterrey, Mexico. He holds a bachelor degree in Physics Engineering and a doctoral degree in Education both from Tecnologico de Monterrey. Dr. de la Garza has been recognized by the government as a member of the Researchers' National System in Mexico (SNI). He also actively participates in the different initiatives of the University mainly those related to interdisciplinary approach of teaching and learning, looking to close the gap between how knowledge is created and how students learn. His main research areas are a) models and modeling, b) learning environments and c) problem solving.

\section{Prof. Genaro Zavala, Tecnologico de Monterrey (ITESM)}

Professor of the Physics Department at the Tecnologico de Monterrey. He is a member of the National Research System in Mexico and is the leader of the Physics Education Research and innovation Group. He has 68 papers in journals and proceedings, 6 books, 7 book chapters, 135 presentations in Mexico, Korea, Denmark, Hungary, Cuba, United States, Ecuador, Chile and Argentina and 26 workshops in Mexico, Chile and Argentina. He has participated obtaining projects funded by the European Consortium of Innovative Universities, HP Development Company, Agencia Española de Cooperación Internacional para el Desarrollo and the University of Arizona. He is a member of the Mexican Council of Educational Research, Vicepresident of the Latin American Physics Education Network (LAPEN), coordinator of the Evaluation of Learning and Instruction Topical Group within the International Research Group on Physics Teaching (GIREP for French); member of the American Association of Physics Teachers (AAPT) in which he was member and president of the International Committee (2006-2008), president of the committee in 2008, member and president of the Philanthropy Committee (2011-2013), member of the Membership and Benefits Committee (2012-2015), founding president of the American Association of Physics Teachers, Mexican section. In the AAPT he is currently a member of the Research in Physics Education Committtee (RiPE) and elected member of the Physics Education Research Leadership Organizing Council (PERLOC). He is a member of the Consejo Nacional de Ciencia y Tecnología (CONACYT) Network on Information Technology, and coordinator of the Science Education Community of the Corporación Universitaria para el Desarrollo del Internet (CUDI). The main area of interest of Prof. Zavala is Physics Education Research in which he studies students' conceptual understanding, designs and implements assessment tools in education, researches on the use of technology in the classroom and conducts research on the acquisition of skills by university students in active learning environments. 


\section{Dr. Cynthia Concepción Castro, Tecnologico de Monterrey, Campus Monterrey}

Cynthia Castro Concepción Ling is Professor of the Mathematics Department of the School of Engineering ITESM Campus Monterrey (ITESM). She graduated from the Engineering in Electronics and Communications and Electronic Systems Master majoring in Telecommunications both degrees from ITESM. Currently, she has a PhD in Educational Innovation, she is coordinator of matter Multivariable Calculus and has over 10 years of experience in education where she has participated as a professor in the departments of Mathematics, Physics and Electrical Engineering. Also, she has conducted research for new learning strategies oriented Model TEC 21, implemented in the courses of engineering careers. She has promoted innovation to conduct and participate in the redesign of courses Engineering. In addition, she has been responsible for leading master's thesis at the Graduate Program of the EGE Virtual University, Campus Monterrey. Finally, she has worked in the industry in the sector of Telecommunications performing engineering design and implementation on wireless networks. 


\title{
Fis-Mat Integrated Physics and Mathematics: A proposal for a curricular sequence
}

\begin{abstract}
This proposal is a project in an early stage. The curricular sequence consists of designing and implementing three integrated courses of Physics and Mathematics corresponding to the first three university courses for those disciplines. The first integrated course, Fis-Mat 1 (short for Physics and Mathematics in Spanish), combines the first course of Physics and the first course of Calculus for engineering students, and it has been taught once a year since 2012. The goal for the curricular project is to complete a sequence of three Fis-Mat courses corresponding to the first three courses of Physics and the three Calculus courses for engineering students. So far, we have gained experience in a) implementing Modeling Instruction as well as teaching from a Models and Modeling perspective, b) taking advantage of the classroom settings, c) tailoring the activities to enhance active learning, d) using the technology and the laboratory equipment in an efficient and meaningful way, and e) designing activities that provide formative and summative assessment to all (students, teachers, and researchers).
\end{abstract}

The main goal of the Fis-Mat curricular sequence is to teach what is needed when it is needed through active learning. The secondary goals are to: a) improve students' abilities to make connections between physics and mathematics in a meaningful way, b) provide students with educational tools to help them overcome the conceptual difficulties that have been reported when the two courses are taken separately, c) foster a deeper understanding of the physical and mathematical concepts applied in engineering practices, and d) develop successful learners by helping students become knowledgeable, self-determined, strategic, and empathetic thinkers who know how to work collaboratively.

Having successfully implemented Fis-Mat 1, we propose expanding Fis-Mat from one course to three courses. That will require a reorganization of content for the three calculus courses and the physics courses, to truly integrate both disciplines in terms of models.

\section{Introduction}

The subjects of Physics and Mathematics are a fundamental part of the core curriculum of engineering programs. The concepts and procedures developed in those subjects are applied in other courses of the program. Hence, learning and understanding the material covered in those fundamental courses is relevant for all engineering students. However, Physics and Mathematics are often taught as separate courses, creating shifts between the concepts and procedures taught in one course and needed in the other at a particular time, as well as a lack of connections between applications and approaches of the same idea from these disciplines. To bridge the gap between Physics and Mathematics, the proposal is to design a sequence of three university courses that integrate content and applications from the perspective of models and modeling (Fig. 1). Fis-Mat stands for Physics and Mathematics in Spanish. Each of these three Fis-Mat courses fulfills the curriculum of Physics, Mathematics and Physics laboratory for students of first, second and third semester of engineering programs. The curricular design of the integrated courses is flexible to integrate at least all the contents from each of the corresponding Physics 
and Mathematics courses. Thus, each of the Fis-Mat courses covers the complete curriculum of each of the separated Physics and Mathematics courses for the first, second and third semester of engineering programs, respectively.

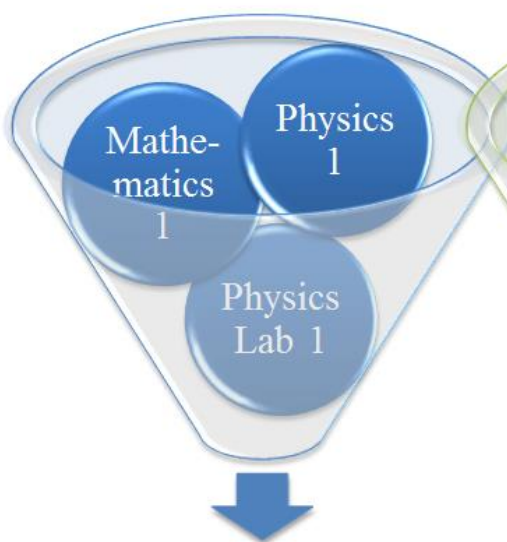

FIS-MAT 1

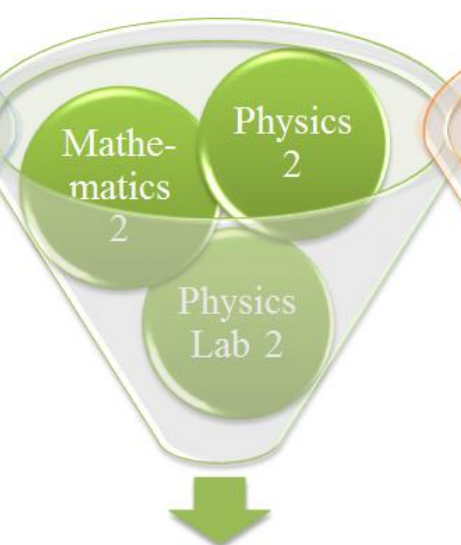

FIS-MAT 2

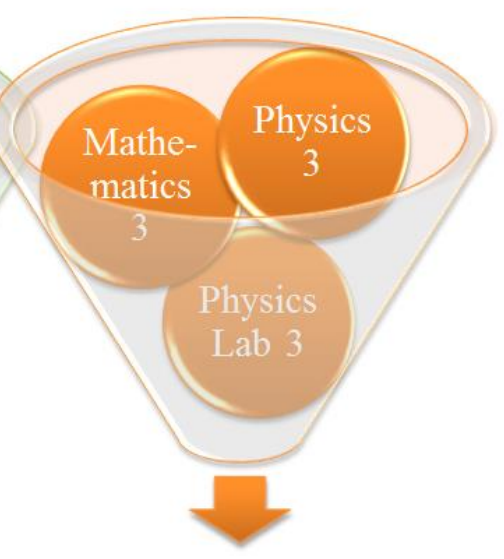

FIS-MAT 3

Figure 1. The three integrated courses of Physics and Mathematics (Fis-Mat) organize the contents of Mathematics, Physics and Physics laboratory in a coherent and timely manner.

The idea of teaching integrated courses is not new ${ }^{1,2,3,4,5}$. There have been numerous efforts; some of them integrate two, three, or even more courses. Also, the degree of the integration varies; some efforts integrate final projects, while others use a particular topic of the course and some others try to integrate the entire course. Dunn and Barbanel stated that in most universities, physics and mathematics courses are taught separately, and there is little or no communication between academic departments to know what or how their colleagues teach relevant courses. This separation results in substantial differences on how to approach a context and the notation used, which can cause difficulties in the transfer of knowledge between the courses of mathematics and physics ${ }^{6}$. Even more, it often occurs that when the physics course requires some concept or mathematical procedure, this idea has not been covered in the math class yet or the approach to this idea happens to be different, making it harder for the student to recognize the connection $^{7.8,9,10,11,12,13}$.

Bertrand Russell said, "Physics is mathematical not because we know so much about the physical world, but because we know so little; it is only its mathematical properties that we can discover." Fis-Mat courses use mathematics as a tool to analyze physical phenomena. It takes into account students' prior knowledge and encourages students to make strong predictions and to think critically about a phenomenon. This combination of mathematical and physical content uses mathematics as a powerful tool that offers the concepts and operations needed to analyze and understand physical models. The instructional pedagogy is Modeling Instruction ${ }^{14,15,16}$ and the main structure of the curriculum focuses on models (physical models and mathematical models). That is, instead of thinking of a linear curriculum to cover, Fis-Mat takes main concepts and models to unveil related concepts, procedures and applications ${ }^{10,17,18}$. This approach allows students to engage actively in the processes of conjecturing, testing and thinking revision ${ }^{17,18,19}$. Models and modeling perspective $\mathrm{e}^{18,19,20,21}$ is used to develop mathematical models and concepts by having students: a) work on real life problematic situations that extend their way of thinking, 
b) analyze collected data from real situations that allows them to explore patterns and regularities of the mathematical models, and c) identify the use of mathematical and physical concepts and procedures by solving problems using the constructed models.

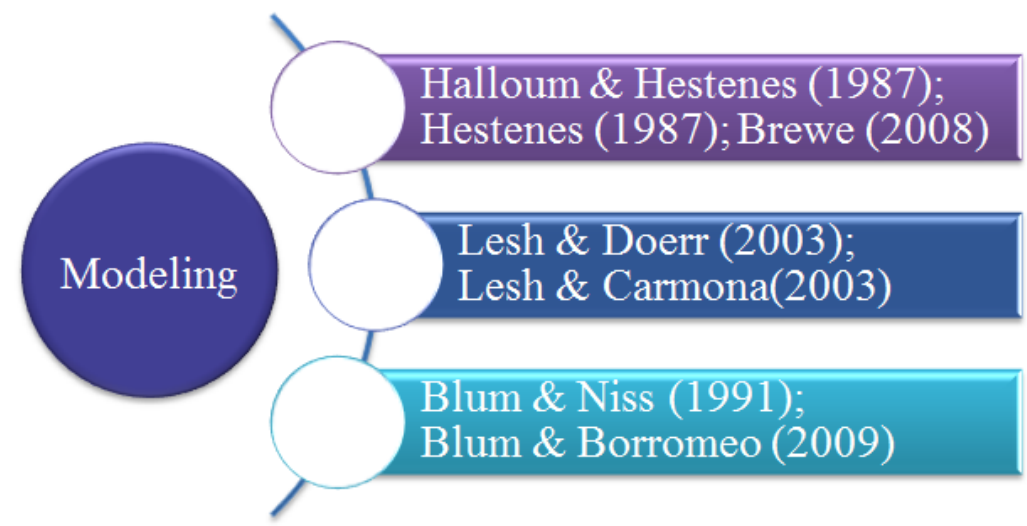

Figure 2. Main modeling perspectives that serve as the foundation of the integrated Physics and Mathematics courses.

\section{Course objective}

The objective of the course is to teach what is needed when it is needed through active learning that could encourage the connection between physics and mathematics in a meaningful way for first-year engineering students. Therefore, the goals of the Fis-Mat content are: a) to improve students' abilities to make connections between physics and mathematics, b) to deliver a flexible course that provides students with educational tools to help them overcome the conceptual difficulties that have been reported when the two courses are taken separately, and c) to foster a deeper understanding of the physical and mathematical concepts applied in engineering practices.

The primary goals of the Fis-Mat pedagogy are: a) to introduce students to the engineering way of thinking to approach problems, b) to create a learning environment that places students at the center of the teaching and learning process, c) to increase students' motivation to advance in their engineering studies, d) to develop successful learners by helping students to become knowledgeable, self-determined, strategic, and empathetic thinkers who know how to work collaboratively, and e) to align assessment (formative and summative) to the content and teaching strategies.

The main goals for the classroom environment are: a) to foster communities of learning, b) to facilitate collaborative learning, c) to allow students to perform experiments to test their predictions, and d) to empower students to take charge of their own learning.

\section{Course approach}

The curricular design involves several elements that make Fis-Mat a unique innovation. Course content. Fis-Mat content covers (at least) all of the topics from a Physics 1 course and a Mathematics 1 course for engineering students. Fis-Mat uses the physics curriculum as its 
backbone, with mathematics providing support for idea-building and operations. The mathematics concepts and procedures are studied from an application perspective.

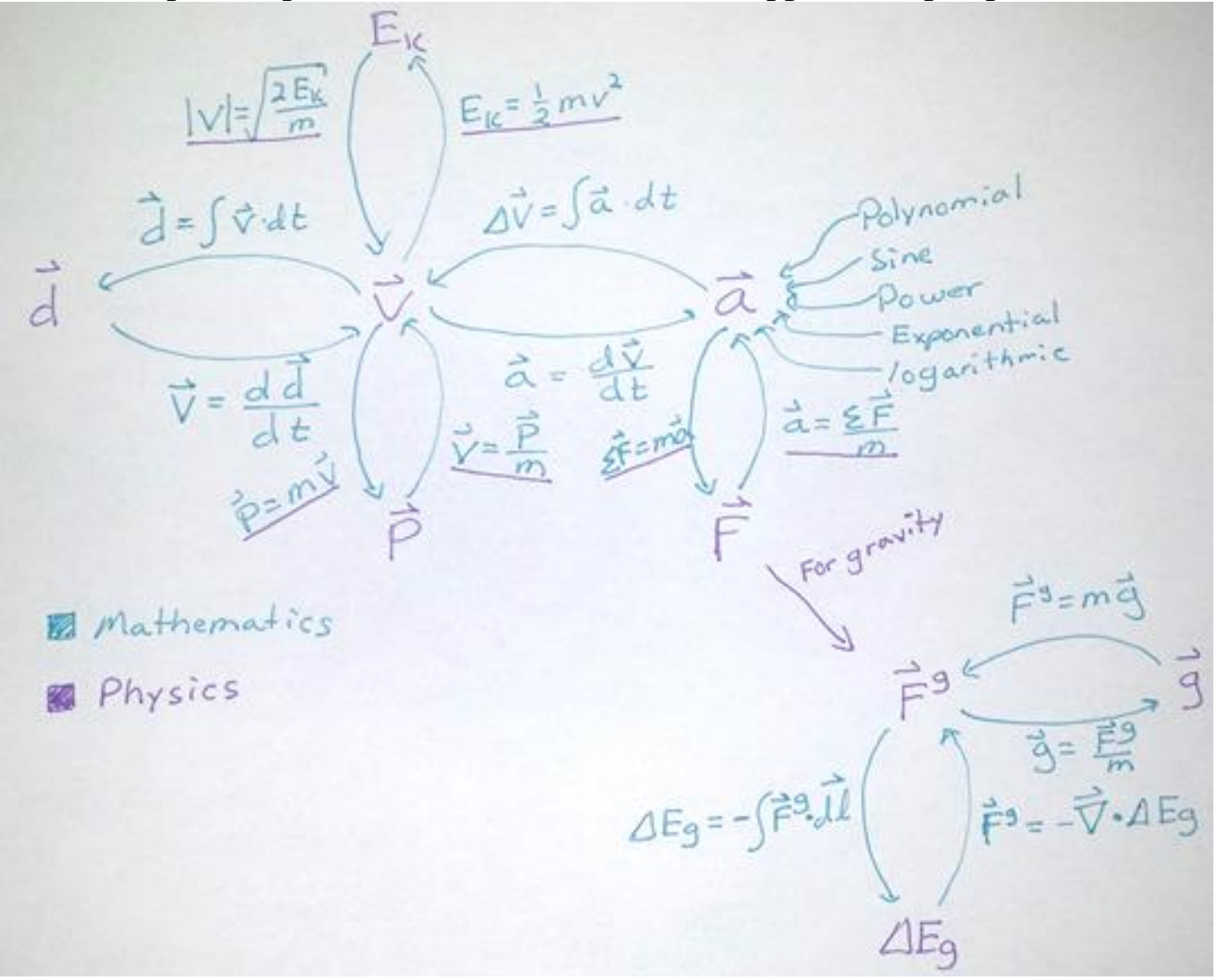

Figure 3. Concept map of connecting ideas of the first course of the integrated Physics and Mathematics curricular sequence.

Teaching strategies. A Physics professor and a Mathematics professor attend all the sessions of the course to teach what is needed when it is needed. Professors' collaboration outside and inside of the classroom is fundamental for an almost seamless integration of the physics and mathematics content ${ }^{22}$.

Classroom environment: To facilitate collaboration, the classroom has round tables to seat three groups of three students per table. Students work collaboratively most of the time. Lecture time is kept to a minimum and does not exceed more than 15 minutes at a time. Students report their work using portable whiteboards and a whole-class big-circle discussion is held to share ideas, solutions, ask questions, clarify questions, and summarize main concepts worked in the activity. Professors ask students to lead the discussion, empowering them and allowing them to develop communication skills. 


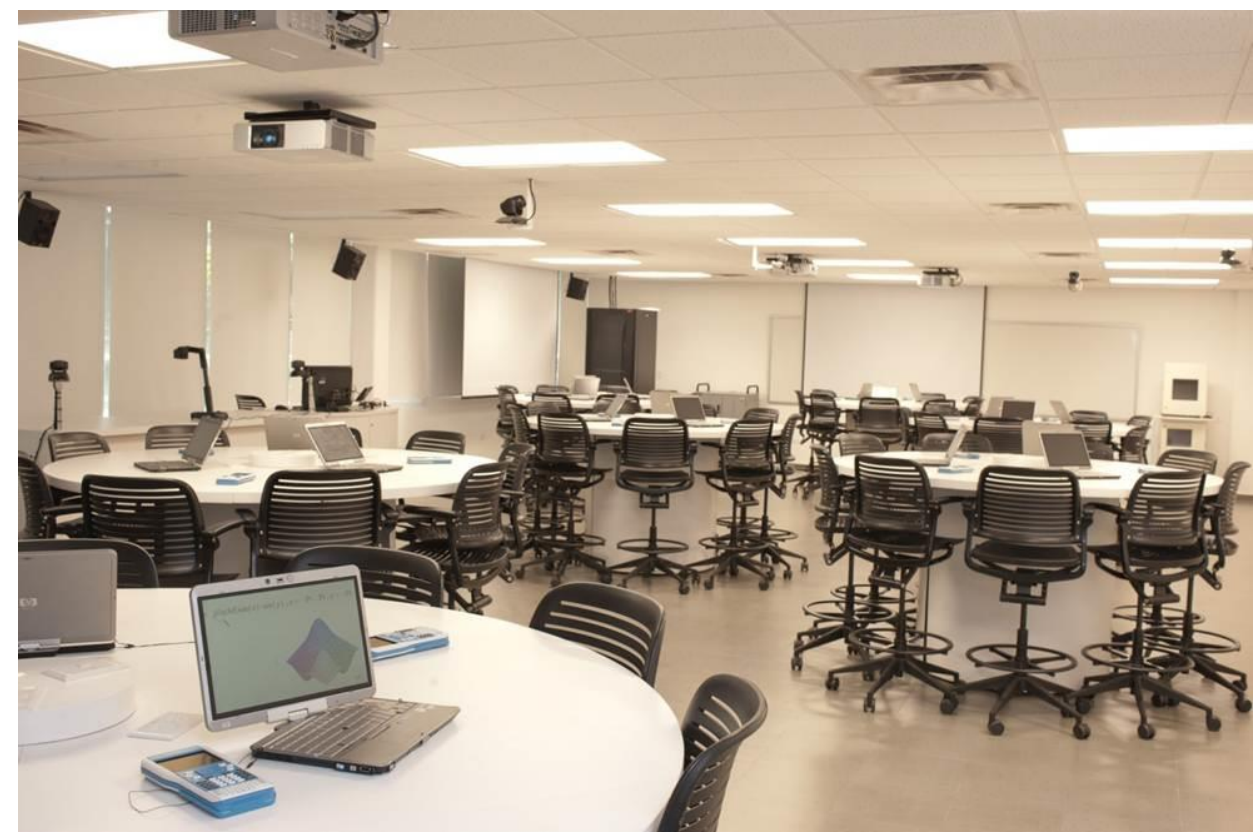

Figure 4. Classroom seating shows round tables that seat nine students. Tables are high to allow students to work standing or seated.

Use of technology and lab equipment: The classroom is equipped with notebooks, main computer to connect all notebooks, graphing calculators and a system to connect all calculators, laboratory equipment for experiments, four projectors, voting system with clickers, document camera, demonstration table, big tablet for the instructors, video conference system, wired and wireless internet, and one of the tables has microphones and cameras to record students' work. At least once a week students run experiments to collect and analyze data.

Evaluation: To align the pedagogy, content, classroom setting, and use of the technology, students present individual and collaborative integrated partial exams and work and present a collaborative final project. Formative assessment is promoted on a daily basis to inform professors as well as students about what is understood, what needs to be reviewed, what works and what does not.

\section{Faculty collaboration and engagement}

The Fis-Mat Project has brought together academic departments that traditionally have worked together: the Department of Physics and the Department of Mathematics ${ }^{20,21,22}$. Moreover, since the Fis-Mat course is offered to engineering programs with priority for students enrolled in the Innovation and Development Engineering Program, we are working together to promote that FisMat students become successful learners and creative engineers.

All sessions are based on active learning. At the beginning of the semester, faculty implements activities to foster students' collaboration as well as self-regulation. Once the students are empowered, the sessions run very smoothly, and student's dependence of the faculty's approval decreases significantly. The main idea of the course's structure is about models: mathematical models and physical models. We emphasize that models provide us with a bigger window to 
understand and analyze phenomena and help students to construct more robust and complete models of every situation that they encounter during the course. This promotes better and strong connections among concepts and consistency among representations.

At the end of each semester, each collaborative group presents their project. This is done as a formal presentation as well as in poster fair format. Students prepare a written report and an oral presentation to explain their approach to solving the problem. Working on the final project challenges them to truly apply all they have learned, concepts, representations, solving strategies, collaborations, communication of ideas, etc. Faculty and other students are invited to attend the oral presentations or poster session.

In general, students' comments are positive and consider the Fis-Mat course as a good learning experience. Students argue that Fis-Mat reduces boundaries between physics and mathematics, helping them to better understand the application and need for the mathematics content. Students mentioned that at first it is hard to follow, but once they understand the model approach, it gets easier. They also recognize that by working in this way, the need for memorizing formulas is reduced to a minimum.

\section{Project impact /results}

Two main results have been found: one is based on students' learning, attitudes and competences and the second one is related to those of the participant faculty.

In general, the participant faculty members were pleased with the experience. We have taken note of aspects that need improvement and of others that will be retained for future implementations. Moreover, we are revising and adjusting the activities so that the course content is presented smoothly, with fewer abrupt changes between topics.

Academic achievements. The Department of Physics coordinates the final examinations for all courses, all sections. We compared Fis-Mat students' performance (experimental group) with Physics students that took the same Physics 1 course, in a non-integrated format (control group) and found that the Fis-Mat students performed as well or higher that the control group, but not as high as honors or Physics majors of the same course. With respect to mathematics, students were able to answer the same exam and in many problems performed as well or better than students in a regular calculus course. Faculty involved in the Fis-Mat Project consider these results as positive and encouraging, since students were able to learn and apply the main physics and calculus concepts, despite the fact that the instruction placed less emphasis on typical physics and math problems and more on the applications.

Competences. Students became more effective communicating their ideas and learning how to collaborate with peers. This was evident during the big-circle discussion; as time advanced, students' questions were more elaborated and showed a deeper understanding, their communication became more organized and structured, and their models were more robust (more coherent representations) towards the end of the semester.

Students' appreciation of the course could also be counted as a positive result. 


\section{Students' opinions regarding the integrated course}

The research group was interested on knowing students' opinion about their experience during the integrated Physics and Mathematics course. To that end, a Google Survey was implemented and sent to all the students who had taken the integrated course since it was offered for the first time. From the 166 students we invited to participate, 83 answered (50\%). The first part of the survey consisted of Likert-type questions in which students had to choose from 1 (very infrequently) to 7 (very frequently) for each question according to their experience in the course. We chose six items from the 13 questions in the first part of the survey because they focus on key elements of Fis-Mat. These statements and results are presented in the Table 1.

\begin{tabular}{llc}
\hline Item & Question & Average \\
\hline 2 & How frequently did you have collaborative discussions in the classroom? & 6.3 \\
3 & How frequently did you collect and analyze data with sensors and computers? & 5.4 \\
6 & How frequently did you participate in activities solving problems? & 6.6 \\
7 & How frequently did you feel that missing this class would have affected your & 5.6 \\
& learning? & 6.6 \\
10 & Interact with my classmates in the classroom & 6.3 \\
\hline
\end{tabular}

Table 1. Average of students response to six questions regarding classroom activities $(\mathrm{n}=83$ responses).

The course promotes collaborative work among students. Since the average for all students in question 2 is 6.3 out of 7 , there is evidence that students think that collaborative work is happening in the class. The course promotes the use of models and the use of technology. Question 3 is related to both of them. Students use sensors and computers (technology) and analyze data and construct models. In this case the average for this question is 5.4 out of 7 . Problem solving is another competence that Fis-Mat promotes and fosters. The agreement of students (6.6 out of 7) in question 6 evidences that they believe that problem solving is happening in the course. The last question on this first part is question 7. Fis-Mat is designed with such a structure that promotes learning inside the classroom. Students who missed the class know that their understanding would be affected (5.6 out of 7). Fis-Mat promotes students interactions and value students' work, as shown in the results of items 10 and 11. Students' perception of the interactions among students in the classroom is close to 7.

The second part of the survey was composed of eight Likert-scale items, where a statement was presented and students had to completely disagree (1) to completely agree (7). In this case, we discuss five items out of eight (Table 2).

\begin{tabular}{llc}
\hline Item & Question & Average \\
\hline 1 & The integrated Fis-Mat course is a useful way of teaching and learning. & 5.7 \\
3 & Fis-Mat is not an adequate course for physics and math classes. (Negative & 2.7 \\
& statement). & 5.4
\end{tabular}


6 The integrated Fis-Mat course is not for me. (Negative statement).

$7 \quad$ Performing experiments in the classroom seems good.

Table 2. Average of students response to five questions about the methodology of the integrated Physics and Mathematics course ( $\mathrm{n}=83$ responses).

By their structure, items 1, 4 and 7 are positive statement, while 3 and 6 were negative statements. Analyzing the negative statements, item 3 asked students their opinion on integrating the two courses, that is, this item read "Fis-Mat is not an adequate course for physics and math classes." On average, students responded 2.1 which in terms of the Likert-scale indicates disagreeing with the statement. Therefore, students consider that it is adequate to integrate physics and mathematics in the way that Fis-Mat does. Question 6 is a very revelatory statement which reads: "Fis-Mat course is not for me." In this case, the average students' response is closed to "somewhat in disagreement" that in the Likert-scale is represented by 3. Although it is still a disagreement of the students, that opinion is not very strong. This is something we have to analyze to improve our course.

With respect to the positive statements, items 1 and 4 are closely related and also the results showed that students" perception of the course is between "somewhat agree" and "agree." These indicate that students in general considered that the integrated course is useful, and it helps them to understand better the subjects. Item 11 targets a main element of the Fis-Mat course: the high frequency of experimentation that students do in the course. On average, students' response was between "agree" and "completely agree," which indicate that they value the experimentation aspect of the course.

The last five items related to the general opinion of the course: a True/False (T/F) statement, a grading statement, strengths, weaknesses, and general comments of the course. The T/F statement asked students whether they would recommend the course to other students or not. According to the results, $84 \%$ of students indicated that they would recommend the course to other students. That means that $14 \%$ of students would not recommend the course. We have to focus on these opinions to improve our results. The grading statement asks students to evaluate the course on a 1 to 100 scale. The average grade of the course according to the students is 86 out of 100. Although the grade is high, we take this as a challenge to continue improving.

The survey included two open-ended questions for which students had to write their comment on the strengths and weaknesses of the Fis-Mat course. Some of students comments regarding the strengths of the course read as follows:

"It helps you to really understand what's going on in math and physics (since t's unreal that math and physics do not interact with each other), it is somewhat difficult at the beginning but later, once you got it, it is easier."

"Learn the why of things and not just memorize equations."

"Having two teachers who know their subjects well and they knew very well how to integrate a single course."

"You learn to learn and to self-regulate."

"By integrating the two courses it is easier to relate concepts between the two materials and we hardly feel the difference between mathematics and physics, we just learn from both." 
Based on this sample of statements, we can argue that students are getting the idea that learning math with no context and learning physics avoiding math is not the way to go. Integrating the courses is one of the most important goals of the course, and students seem to understand this. Constructing a word cloud using students' responses shows us another way to identify visually the elements of the course that students appreciate the most (Fig. 5).

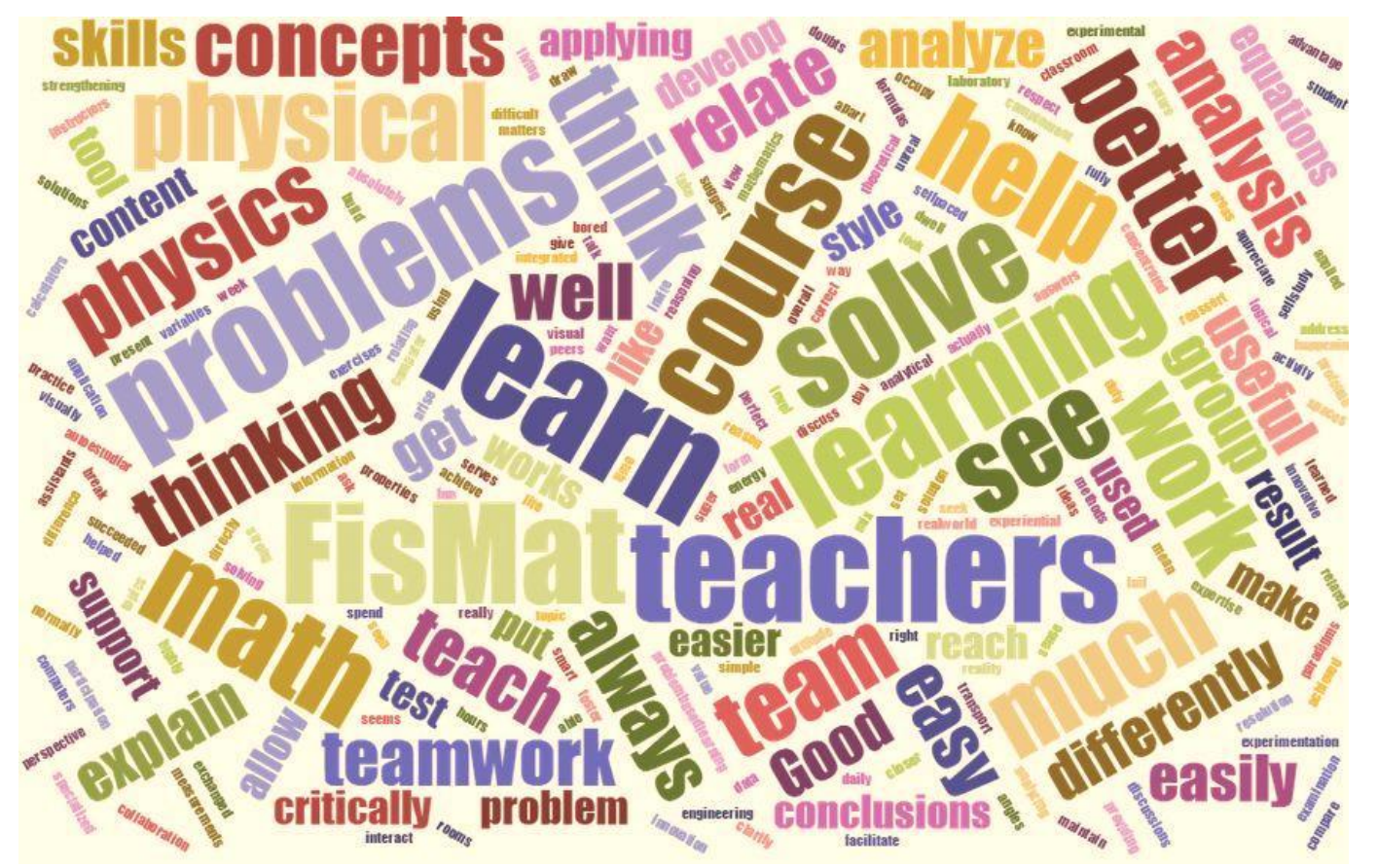

Figure 5. Word cloud using students' responses about the strengths of Fis-Mat.

Regarding the opportunities for improvement and weaknesses of the course, students commented that:

"In some classes, maybe because of the contents, math and physics were not well integrated and in the change from one discipline to the other, the inertia of the class was broken."

"Final conclusions (by the teachers) should be at the end of the class."

"After some issues, reaffirm the conclusions we should have deducted and explain the purpose of what we were doing. (It is done already, but I think you should spend more time on it)."

"From time to time, there is much confusion among students. I think it would be nice if occasionally teachers explained the topics a little more in order to avoid confusion, because sometimes it's not clear what we want to get from the activities."

This statement is an indicator that we have to work more to integrate fully the two disciplines. Also, we need to pay attention to summarize final remarks on a topic in a clearer way.

Some students understood the question as opportunities for improvement that the course addresses. Since those comments are similar to the ones given for the last question of the survey, general comments, we include here some of students ideas about Fis-Mat. This is what they said: 
"Expand it to other areas. Build an educational model based on this that is replicable in other disciplines."

"The opportunities for improvement of this course are that it would make you think differently. This course makes you mix physics and math so that you have a mean to analyze and solve different problems."

"It makes you think completely differently and more critically when facing a problem."

"In Fis-Mat I learned experiences and knowledge which are much more important than knowing equations. It gives you a different perspective to attack problems."

"The class has helped me put together all that I had learned before. That is, now, all I see, makes sense."

"Very good course, much better than to take them separately. They [the teachers] challenge us every day in different, and fun, ways."

"Thanks, because I'm totally fascinated with the course, I had never taken a class like this and it has taught me to think very differently without needing to memorize formulas. I liked it a lot. I can say that I have never been unwilling to learn the class."

These statements are very powerful coming from the students. They capture precisely what the Fis-Mat course is all about. These comments let us know that we are moving in the right direction. We have to continue improving the Fis-Mat experience and also expand it to the complete sequence (Fis-Mat 1,2 and 3), but working with big ideas, as well as models, and being receptive to students' comments, we are positive that we will be able to structure and deliver a better learning experience for all engineering students.

\section{Next steps}

The project is at an early stage. It has been taught once a year since August 2012. The goal is to complete a sequence of three Fis-Mat courses corresponding to the first three courses of Physics and the three Calculus courses for engineering students (Fig. 6). So far, we have gained experience in: a) implementing Modeling Instruction as well as teaching from a Models and Modeling perspective, b) taking advantage of the classroom settings, c) tailoring the activities to enhance active learning, d) using the technology and the laboratory equipment in an efficient and meaningful way, and e) designing activities that provide formative and summative assessment to all (students, teachers, and researchers).

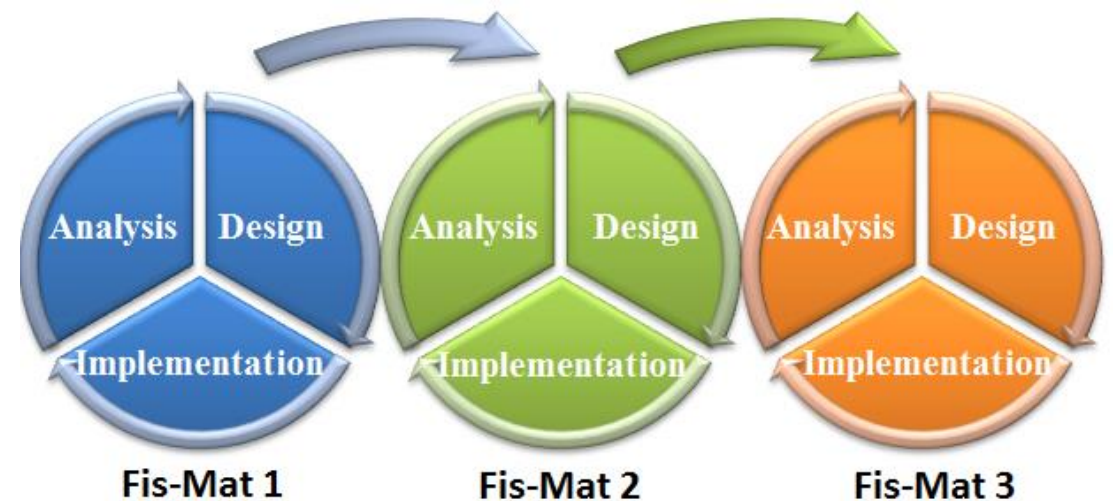

Figure 6. Strategy to take into account what we have learned in the first integrated course into the second and third courses. 
Taking into account students' comments, we need to work more on a seamless integration of the two courses. We understand that for some topics this may not be possible, but we can certainly make a more smooth transition.

With the experience that we have gained since 2012, when we started working on this project, we feel that now we can think about expanding Fis-Mat from one course to three courses (Fig 6). That will require a reorganization of content for the three calculus courses as well as for the physics courses, to fully integrate both disciplines in terms of models.

\section{Bibliography}

1. J. Carpenter, "Integrating Calculus and Introductory Science concepts", Proceedings 2007 Annual Meeting of the American Society for Engineering Education, ASEE (2007).

2. L. Gentile, L. Caudill, M. Fetea, A. Hill, K. Hoke, B. Lawson, O. Lipan, M. Kerckhove, C. Parish, K. Stenger, \& D. Szajda, "Challenging Disciplinary Boundaries in the First Year: A New Introductory Integrated Science Course for STEM Majors", J. College Science Teaching, 41(5), 2012, pp. 44-50.

3. M. W. Ohland, R. M. Felder, M. I. Hoit, G. Zhang, \& T. J. Anderson, "Integrated Curricula in the SUCCEED Coalition", Proceedings 2003 Annual Meeting of the American Society for Engineering Education, ASEE (2003).

4. D. Pines, M. Nowak, H. Alnajjar, L. I. Gould \& D. Bernardete, "Integrating Science and Math into the Freshman Engineering Design Course", Proceedings 2002 Annual Meeting of the American Society for Engineering Education, ASEE (2002).

5. M. L. Temares, R. Narasimhan \& S. S. Lee, "IMPaCT - A Pilot Program", 1996 ASEE Annual Conference Proceedings, ASEE (1996).

6. J. Dunn \& J. Barbanel. One model for an integrated math/physics course focusing on electricity and magnetism and related calculus topics. Am J of Phys, 68(8), 749-757, (2000).

7. L. Cui, N. S. Rebello, \& A.G. Bennett, College students' transfer from calculus to physics. En L. Cui, N. S. Rebello, y A. G. Bennett (Eds.), Physics Education Research Conference, 818, 37-40, AIP (2005).

8. T. Dray, B. Edwards and C. A. Manogue, "Bridging the gap between mathematics and physics", (2008).

9. R. Beichner, L. Bernnold, E. Burniston, P. Dali, R. Felder, J. Gastineau, J., et al., Case study of the physics component of an integrated curriculum. Physics Education Research Supplement to American Journal of Physics, 67(7), S16-S24, (1999).

10. W. Blum, \& M, Niss, Applied mathematical problem solving, modelling, applications, and links to other subject: States, trends and issues in mathematics instruction. Educational Studies in Mathematics, 22(1), 3768, (1991).

11. J. Mestre, Implications of research on learning for the education of prospective science and physics teachers. Physics Education, 36(1), 44-51, (2001).

12. M. S. Sabella and E. F. Redish, "Literature Review: Student Understanding in Calculus", 2002. Retrieved on august 24, 2007 from http://www.physics.umd.edu/perg/math/calc.htm.

13. J. Martínez-Torregos, R. López-Gay and A. Grass-Marti, "Mathematics in Physics Education: Scanning Historical Evolution of the Differential to Find a More Appropriate Model for Teaching Differential Calculus in Physics", Science \& Education, 15, 447-462 (2006).

14. Halloum, I. A., y Hestenes, D. (1987). Modeling instruction in mechanics. Am J of Phys, 53(11), 1043-1055.

15. D. Hestenes, Toward a modeling theory of physics instruction, Am J of Phys, 55(5), 440-454, (1987).

16. W. Blum, \& R. Borromeo Ferri, Mathematical modelling: Can it be taught and learnt? Journal of Mathematical Modelling and Application, 1(1), 45-58, (2009).

17. E. Brewe, Modeling theory applied: Modeling instruction in introductory physics". Am J of Phys, 76(12), 1155-1160, (2008).

18. R. Lesh, \& H. M. Doerr, Foundations of models and modeling perspectives on mathematics teaching, learning, and problem solving. In R. Lesh \& H. Doerr (Eds.), Beyond constructivism: Models and modeling perspectives on mathematics problem solving, learning, and teaching, 3-33, (2003).

19. R. Lesh \& G. Carmona, Piagetian conceptual systems and models for mathematizing everyday experiences. In R. Lesh and H. Doerr (Eds.), Beyond constructivism: Models and modeling perspectives on mathematics teaching, learning, and problem solving. Mahwah, NJ: Erlbaum, (2003). 
20. A. Dominguez, J. De la Garza, \& G. Zavala. Models and Modelling in an Integrated Physics and Mathematics Course. In G.A. Stillman, W. Blum, \& M. Salett Biembengut (Eds.), Mathematical Modelling in Education Research and Practice: Cultural, Social and Cognitive Influences, International Perspectives on the Teaching and Learning of Mathematical Modelling (pp. 513-522). New York: Springer. (2015).

21. A. Dominguez, \& J. De la Garza. Closing the gap between physics and calculus: Teaching innovations in an integrated course. Proceedings of the 122th ASEE Annual Conference and Exposition. Seattle, WA. (2015).

22. A. Dominguez, G. Zavala, \& J. A. Alanís. Integrated Physics and Math course for Engineering Students: A First Experience. Proceedings of the 120th ASEE Annual Conference and Exposition. Atlanta. (2013). 